\title{
Hospital-acquired Hyponatremia in Pediatric Intensive Care Unit
}

\author{
Anil Sachdev, Nagaraj Pandharikar, Dhiren Gupta, Neeraj Gupta, Suresh Gupta, Shekhar T. Venkatraman \\ Department of Pediatrics, Sir Ganga Ram Hospital, New Delhi, India
}

\section{Abstract}

Objective: The objective of the study was to evaluate the etiology of hospital-acquired hyponatremia (HAH) and its effects on morbidity and mortality in the Pediatric Intensive Care Unit (PICU) patients. Design: This study design was a prospective observational case-control study. Setting: this study was conducted at tertiary care PICU. Materials and Methods: All consecutive cases admitted with at least one measured serum sodium $\left(P_{\mathrm{Na}}\right)$ value were evaluated. Those with normal admission $P_{\mathrm{Na}}$ were followed till they develop hyponatremia $\left(P_{\mathrm{Na}}<35 \mathrm{mEq} / \mathrm{L}\right)$ 7 days or PICU discharge whichever was earlier. Results: During the study period, 123 (19.6\%) cases developed HAH and 126 patients remained isonatremic (control group). The admission $P_{\mathrm{Na}} 138.8 \pm 3.03 \mathrm{mEq} / \mathrm{L}$ decreased to $132 \pm 2.58 \mathrm{mEq} / \mathrm{L}$ (drop of $6.68 \pm 3.39 \mathrm{mEq} / \mathrm{L}$, $P<0.001)$ in HAH cases. The use of antidiuretic hormone (ADH)-stimulating drugs (odds ratio [OR]: $2.83, P=0.01$ ), postsurgical status (OR: $2.95, P=0.006)$, and fluid intake $\mathrm{ml} / \mathrm{kg}(\mathrm{OR}: 1.0, P=0.001)$ were found to be significant risk factors in HAH group on multivariate analysis. HAH cases had prolonged PICU stay $(P=0.000)$ and mechanical ventilation $(P=0.01)$, but no difference in the mortality when compared to controls. Conclusions: HAH is associated with increased fluid intake, presence of ADH-stimulating drugs or conditions, and postsurgical status and has an adverse effect on the outcome of PICU patients.

Keywords: Antidiuretic hormone, dysnatremia, hyponatremia intravenous fluid, pediatric intensive care, sodium

\section{INTRODUCTION}

Hyponatremia (serum sodium $\left[P_{\mathrm{Na}}\right]<135 \mathrm{mEq} / \mathrm{L}$ ) is more frequent electrolyte abnormality in hospitalized patients and is associated with increased morbidity and mortality. ${ }^{[1,2]}$ Hyponatremic patients are more likely to require intensive care, mechanical ventilation, and have significantly higher chances of increased length of stay, treatment costs, and mortality (3 times compared to patients with normal $\left.P_{\mathrm{Na}}\right) \cdot{ }^{[3-5]}$

Most of the previous studies evaluating incidence of hospital-acquired hyponatremia (HAH) in adult ICUs have shown an incidence of $20 \%-30 \%$ and have also reported poor morbidity and mortality. ${ }^{[6-9]}$

Depending on the definition of hyponatremia, the reported incidence of $\mathrm{HAH}$ in children varies between $10 \%-50 \%$ in various studies and with significant morbidity and mortality. ${ }^{[10-15]}$ Majority of patients included in these studies were those admitted in pediatric wards and emergency units. Studies from Pediatric Intensive Care Unit (PICU) on

\begin{tabular}{|l|l|}
\hline \multicolumn{3}{c|}{ Access this article online } \\
\hline Quick Response Code: & Website: \\
& www.ijccm.org \\
\hline
\end{tabular}

postoperative patients have focused primarily on the effects of hypotonic fluid on serum sodium. ${ }^{[16-18]}$

To the best of our knowledge, there are no studies done to comprehensively evaluate the incidence, etiology, and impact on the outcome of HAH in critically sick children. Hence, in the present study, we aim to investigate the incidence, etiological characteristics, and effect of HAH on the outcome of PICU patients.

\section{Materials and Methods}

This prospective, observational, case-control study was conducted over a year in the PICU of a tertiary care teaching hospital. Institutional Research Ethics Board approved the study. Written informed consent was obtained from parents or

Address for correspondence: Dr. Anil Sachdev, Sir Ganga Ram Hospital, Rajinder Nagar, New Delhi - 110 060, India. E-mail: anilcriticare@gmail.com

This is an open access article distributed under the terms of the Creative Commons Attribution-NonCommercial-ShareAlike 3.0 License, which allows others to remix, tweak, and build upon the work non-commercially, as long as the author is credited and the new creations are licensed under the identical terms.

For reprints contact: reprints@medknow.com

How to cite this article: Sachdev A, Pandharikar N, Gupta D, Gupta N, Gupta S, Venkatraman ST. Hospital-acquired hyponatremia in pediatric intensive care unit. Indian J Crit Care Med 2017;21:599-603. 
guardians for all participants, and assent was obtained from children over 7 years of age if appropriate.

\section{Data collection}

The sample size was calculated to estimate the number of patients required to calculate the incidence of $\mathrm{HAH}$. With $9.3 \%$ incidence of $\mathrm{HAH}$ as per the previous study, an error of $2.5 \%$, and confidence interval of $95 \%$, the estimated sample size was $610 .{ }^{[10]}$ All children between the age group of 1 month to 16 years who received intravenous fluid (IVF) with at least one measured $P_{\mathrm{Na}}$ value at admission were included in the study. All $P_{\mathrm{Na}}$ levels were measured by direct ion selective electrode method. Patients with hyponatremia or hypernatremia at admission were excluded from the study. As per the unit protocol, blood chemistries were monitored 12 hourly. Patients with normal $P_{\mathrm{Na}}$ at admission were further followed till they developed hyponatremia $\left(P_{\mathrm{Na}}<135 \mathrm{mEq} / \mathrm{L}\right)$ for a maximum of 7 days or PICU discharge whichever was earlier. Those who developed hypernatremia $\left(P_{\mathrm{Na}}>145 \mathrm{mEq} / \mathrm{L}\right)$ and without follow-up $P_{\mathrm{Na}}$ values were excluded from the study [Figure 1].

The following data were recorded for the enrolled cohort: age, gender, weight, diagnosis, renal function tests, liver function tests, and random blood sugar levels. The total intake (oral and type and volume of IVF), output, and net balance were recorded. Other parameters such as the presence of antidiuretic hormone (ADH)-stimulating clinical condition, ADH-stimulating drugs, postsurgical state, and the use of $3 \%$ saline were recorded.

As per the unit protocol, half-normal saline $(0.45 \%$ with $5 \%$ dextrose), $0.9 \%$ saline with dextrose (DNS), and normal saline were used as the standard maintenance IVF in age groups $<2$ and $>2$ years, respectively. The volume of maintenance IVF requirement was according to Holliday-Segar formula.

Other parameters such as the use of inotropes, length of stay in PICU, total ventilator days, and final outcome (survival/death)

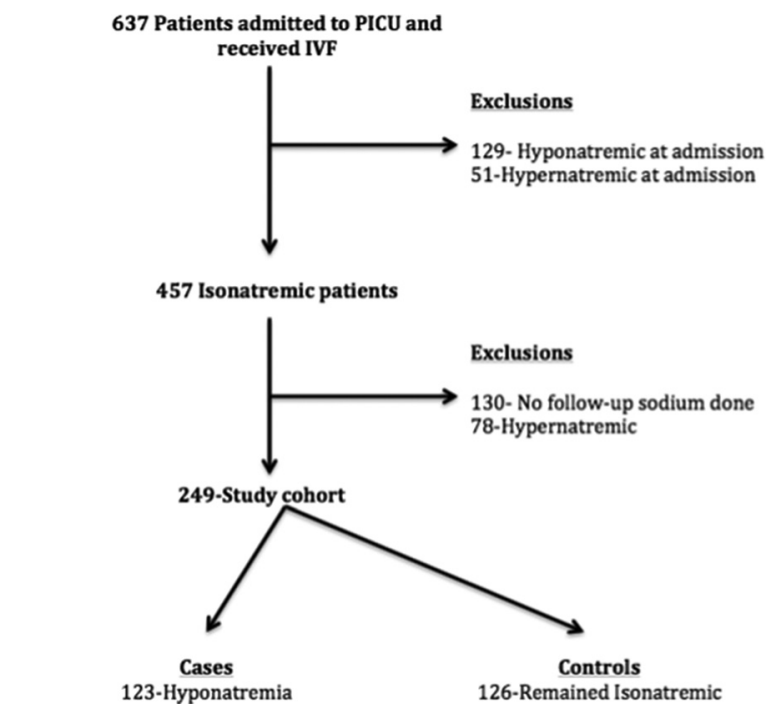

Figure 1: Study flowchart were also recorded. As per the unit protocol for the management of HAH patients, we also did serum osmolality and urinary osmolality, sodium and creatinine to evaluate the sodium excretion status, and rule out pseudohyponatremia. The levels of serum $\mathrm{ADH}$ could not be estimated due to the financial constraints.

\section{Definitions}

Hyponatremia and hypernatremia were defined as $P_{\mathrm{Na}}<135 \mathrm{mEq} / \mathrm{L}$ and $>145 \mathrm{mEq} / \mathrm{L}$, respectively. $\mathrm{HAH}$ was defined as at least one documented value of $P_{\mathrm{Na}}<135 \mathrm{mEq} / \mathrm{L}$ during the hospital stay, at least $12 \mathrm{~h}$ after admission in those with normal $P_{\mathrm{Na}}(135-145 \mathrm{mEq} / \mathrm{L})$ at admission. Acute hyponatremia was defined as the development of hyponatremia within $48 \mathrm{~h}$ of admission. Hyponatremia was classified into $\operatorname{mild}\left(P_{\mathrm{Na}}<131-134 \mathrm{mEq} / \mathrm{L}\right)$, moderate $\left(P_{\mathrm{Na}} 130-125 \mathrm{mEq} / \mathrm{L}\right)$, and severe hyponatremia $\left(P_{\mathrm{Na}}<125 \mathrm{mEq} / \mathrm{L}\right)$.

\section{Statistical analysis}

Data were compiled in an Excel spreadsheet, and statistical analysis was done using SPSS version 23, Chicago, IL, USA. The mean, median, and standard deviation were calculated for the baseline characteristics and other continuous parameters. The Chi-square or Fisher's exact test was used to compare groups with respect to categorical data. Student's $t$-test or ANOVA was used to compare the association between groups with respect to continuous data following normal distribution otherwise Mann-Whitney U-test was used. The factors, which were significant in univariate analysis, were considered for multivariate analysis. Using step-wise logistic regression modeling, we built a final multivariable model evaluating the effect of each variable on the development of hyponatremia. To compare the durations of mechanical ventilation and PICU stay of study cases and controls, Kaplan-Meier curves were plotted. For all the comparisons, the $5 \%$ probability level $(P<0.05)$ was considered statistically significant.

\section{RESULTS}

A total of 637 patients were admitted to the PICU during the study period of 1 year and 457 patients were isonatremic at the time of admission. HAH was observed in $123(19.3 \%)$ patients [Figure 1]. The admission $P_{\mathrm{Na}}$ was $138.7 \pm 2.97 \mathrm{mEq} / \mathrm{L}$ in these patients which decreased to $132.0 \pm 2.5 \mathrm{mEq} / \mathrm{L}$ (difference - $6.6 \pm 3.8 \mathrm{mEq} / \mathrm{L} ; P<0.001$ ). Acute hyponatremia was seen in $64(52 \%)$ patients. Twenty-two (17.9\%) patients had moderate-to-severe hyponatremia whereas rest had mild hyponatremia. Of the hyponatremic group patients, $82(66.7 \%)$ received N/2 whereas rest received NS and DNS. The baseline characteristics were comparable between the two groups [Table 1]. Respiratory and central nervous system disorders were the predominant disease categories in both groups [Table 2].

The patients in the HAH group had a higher incidence of ADH-stimulating drugs $(P=0.02)$, ADH-stimulating clinical conditions $(P=0.03)$, postsurgical status $(P<0.001)$, use of inotropes $(P=0.04)$, fluid intake $(\mathrm{ml} / \mathrm{kg})(P<0.001)$, 


\begin{tabular}{|c|c|c|c|c|}
\hline Category & Variable & Hyponatremic group ( $n=123)$ & Isonatremic group $(n=126)$ & $P$ \\
\hline \multirow{6}{*}{$\begin{array}{l}\text { Demographic } \\
\text { and baseline } \\
\text { characteristics }\end{array}$} & Male (\%) & $86(70)$ & $84(66)$ & 0.58 \\
\hline & Age (years) & $3(0.2-18)$ & $2(0.1-18)$ & \\
\hline & BUN (mg/dl) & $12 \pm 17$ & $9.8 \pm 9.3$ & 0.006 \\
\hline & S.creatinine $(\mathrm{mg} / \mathrm{dl})$ & $0.37 \pm 1.09$ & $0.36 \pm 0.41$ & 0.41 \\
\hline & Total bilirubin (mg/dl) & $0.60 \pm 2$ & $0.61 \pm 4.35$ & 0.84 \\
\hline & PRISM 12 & $10.2 \pm 7.9$ & $5.3 \pm 4.9$ & $<0.001$ \\
\hline \multirow{3}{*}{$P_{\mathrm{Na}}$} & Admission & $138.8 \pm 3.03$ & $139.1 \pm 2.65$ & 0.43 \\
\hline & At end of observation & $132 \pm 2.58$ & $139.07 \pm 2.64$ & $<0.001$ \\
\hline & Fall in $\mathrm{PNa}$ & $6.68 \pm 3.39$ & $0.05 \pm 3.3$ & $<0.001$ \\
\hline \multirow{8}{*}{$\begin{array}{l}\text { System } \\
\text { involved }\end{array}$} & Nervous system & 35 & 42 & 0.41 \\
\hline & Respiratory & 35 & 32 & 0.66 \\
\hline & Gastrointestinal/hepatic & 17 & 16 & 0.85 \\
\hline & Infections/sepsis & 13 & 18 & 0.44 \\
\hline & Cardiac & 9 & 4 & 0.16 \\
\hline & Hemat-oncology & 5 & 5 & 1.00 \\
\hline & Renal & 4 & 0 & 0.05 \\
\hline & Miscellaneous & 5 & 9 & 0.41 \\
\hline
\end{tabular}

Table 2: Frequency of ADH stimulating drugs and ADH stimulating conditions in study cohort and control group

\begin{tabular}{lcc}
\hline Parameter & $\begin{array}{c}\text { Hyponatremia } \\
\text { group }\end{array}$ & $\begin{array}{c}\text { Isonatremia } \\
\text { group }\end{array}$ \\
\hline ADH stimulating drugs & 12 & 5 \\
Diuretics & 7 & 4 \\
Anti-epileptics & 2 & 0 \\
Chemotherapy & & \\
ADH stimulating conditions & 13 & 3 \\
Nervous system & 7 & 11 \\
ICSOL & 6 & 5 \\
Head injury & 6 & 5 \\
Meningoencephalitis & 3 & 4 \\
Seizures & 4 & 2 \\
Hepatic encephalopathy & 1 & 2 \\
Guillian Barre syndrome & & \\
Hydrocephalus & 28 & 15 \\
Respiratory system & 4 & 4 \\
Pneumonia & 1 & 2 \\
Bronchiolitis & 2 & 3 \\
Asthma & & 5 \\
Tuberculosis & 3 & 2 \\
Others & 6 & \\
Malignancy & 2 & \\
Shock & 2 & \\
Hypoadrenalism & & \\
Hypothyroidism & . Intracranial space occupying lesion
\end{tabular}

and output $(\mathrm{ml} / \mathrm{kg})(P<0.001)$ than the isonatremic group on univariate analysis [Table 3]. ADH-stimulating drugs $(P=0.01)$, postsurgical status $(P=0.008)$, and input $(P=0.001)$ were found to be significantly different between the two groups on multivariate analysis [Table 4]. There was no significant difference in the type of IVFs received by the two groups (p-0.50). Hyponatremia developed in $82(52 \%)$ children receiving hypotonic fluids and 41 (46\%) of those receiving isotonic fluids. The patients with $\mathrm{HAH}$ had a longer length of stay in PICU $(P<0.001)$ and higher ventilator days $(P=0.01)$ [Figure 2]. There were three deaths in hyponatremic group and five in isonatremic patients $(P=0.72)$.

\section{Discussion}

In the present study, we found that HAH is common in the PICU patients, and postsurgical status, use of ADH-stimulating drugs, and fluid intake were significant risk factors for the development of HAH. The patients with HAH had prolonged PICU stay and longer mechanical ventilation days.

The incidence of HAH in our study was $19.3 \%$ in all the children admitted to the PICU. The incidence of HAH varies between $10 \%$ and $50 \%$ in different studies depending on the definition of hyponatremia and methodology used. ${ }^{[11-15]}$ The incidence of HAH in our study was higher than the one reported by Hoorn et al. ${ }^{[10]}$ This study evaluated patients for $48 \mathrm{~h}$ and included cases admitted to emergency units and pediatric wards who might be at a lower risk than patients admitted to the ICU.

The incidence of HAH in PICU patients as reported by Rey et al. and Montañana et al. was $43 \%$ and $23 \%$, respectively, which is higher than that found in our study. ${ }^{[17,18]}$ These studies were designed primarily to evaluate the effect of IVF on sodium balance. Furthermore, these studies included patients with hyponatremia at admission which probably predispose them to further hyponatremia. In our study, we included only those patients who were isonatremic at admission.

The incidence of acute hyponatremia $(<48 \mathrm{~h})$ in our study was $52 \%$ similar to the one seen in the study by Bibi et al. $(64 \%) .^{[1]}$ Majority of the patients in our study had mild hyponatremia, 

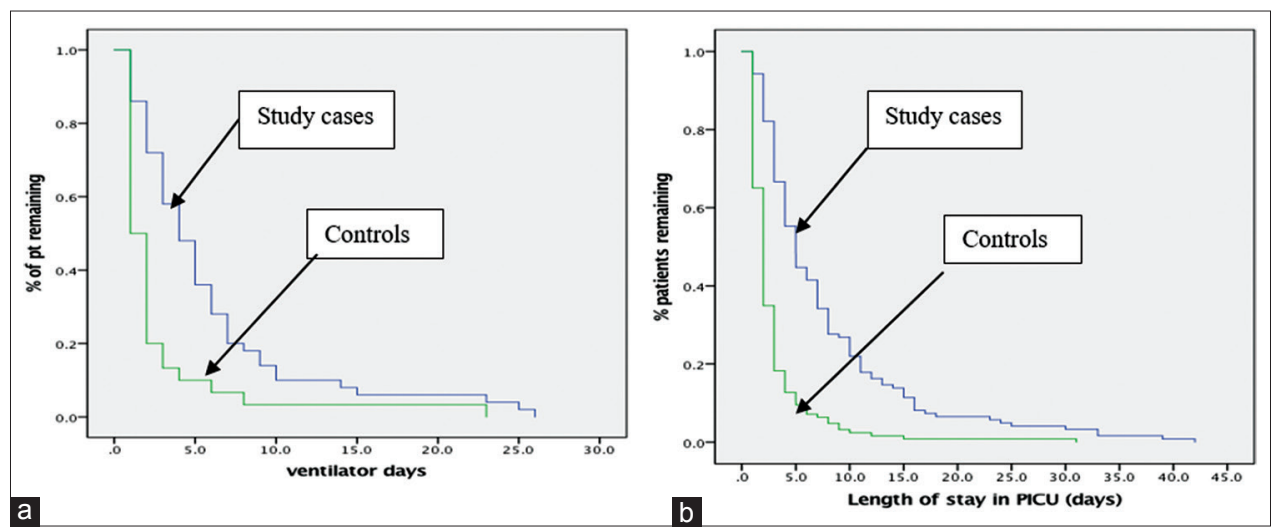

Figure 2: Kaplan-Meier curve for duration of (a) mechanical ventilation (log rank 14.65, $P=0.01$ ) and (b) length of stay in pediatric intensive care unit (log rank 67.22, $P=0.01$ ) of patients with hyponatremia and isonatremia

\begin{tabular}{|c|c|c|c|}
\hline Variable & $\begin{array}{l}\text { Hyponatremia } \\
\text { group }(n=123)\end{array}$ & $\begin{array}{c}\text { Isonatremia } \\
\text { group }(n=126)\end{array}$ & $P$ \\
\hline \multicolumn{4}{|l|}{ Fluid } \\
\hline Type of IVF & DNS 41; N/2 82 & DNS 48; N/2 78 & 0.5 \\
\hline Input (ml/hr) & $57.6(9.6-470.7)$ & $38(4.7-245.3)$ & $<0.001$ \\
\hline Output (ml/hr) & $48.9(7.1-503.7)$ & $31.9(4.2-158.3)$ & $<0.001$ \\
\hline Net balance (ml/hr) & $10(-46.1-176.7)$ & $5.8(-39.1-158.3)$ & 0.02 \\
\hline ADH stimulating drugs & 21 & 9 & 0.02 \\
\hline ADH stimulating conditions & 88 & 73 & 0.03 \\
\hline No. received 3\% saline & 34 & 32 & 0.77 \\
\hline Post-surgical state & 27 & 10 & $<0.001$ \\
\hline No. required inotropes & 12 & 4 & 0.04 \\
\hline Duration of MV (days) & $5.8 \pm 5.7$ & $2.6 \pm 4.1$ & 0.01 \\
\hline LOS in PICU (days) & $7.6 \pm 7.6$ & $2.8 \pm 3.4$ & $<0.001$ \\
\hline No. of patients expired & 3 & 5 & 0.72 \\
\hline
\end{tabular}

IVF: Intravenous fluid; DNS: Dextrose normal saline; N/2: Half-normal saline; ADH: Antidiuretic hormone; MV: Mechanical ventilation; LOS: Length of stay; PICU: Pediatric intensive care unit

\begin{tabular}{|c|c|c|c|}
\hline Parameter & $\begin{array}{l}\text { Odds } \\
\text { ratio }\end{array}$ & $\begin{array}{l}\text { 95\% confidence } \\
\text { interval }\end{array}$ & $P$ \\
\hline ADH stimulating drugs & 2.83 & $1.20-6.63$ & 0.01 \\
\hline Postsurgical status & 2.95 & $1.39-6.62$ & 0.008 \\
\hline Fluid input $(\mathrm{ml} / \mathrm{kg})$ & 1.00 & $1.0-1.1$ & 0.001 \\
\hline
\end{tabular}

ADH: Antidiuretic hormone

$82 \%$ which is similar to those reported in studies of Bibi et al. and Luu et al. (79\% and $82 \%$, respectively). ${ }^{[11,15]}$

Various studies have shown that the use of the ADH-stimulating drugs such as diuretics, opioids, and chemotherapy drugs is known to cause hyponatremia both by virtue of their action and by stimulating ADH release.$^{[19,20]}$ Similarly, clinical conditions such as meningitis, intracranial tumors, head injury, pneumonia, bronchiolitis, asthma, malignancy, hypovolemia, shock, and endocrine abnormalities were associated with hyponatremia in various studies ${ }^{[20-22]}$ However, these conditions and drugs were present even in isonatremic patients also who did not develop hyponatremia. The subgroup analysis done for the same showed that patients in hyponatremic group had multiple risk factors such as higher PRISM score, postsurgical status, higher intake of fluid, and use of inotropes along with these factors which may explain why only these patients developed hyponatremia.

Patients in hyponatremic group had a higher intake of fluids when compared to isonatremic group which is consistent with previous studies which have shown that the presence of free water and $\mathrm{ADH}$ secretion are required for the development of hyponatremia. ${ }^{[10]}$ Postoperative patients are predisposed to hyponatremia due to various reasons such as occult hypovolemia and nonosmotic stimuli such as nausea, vomiting, pain, anesthesia, and opioid analgesics. ${ }^{[23]}$ Such patients admitted in PICU were shown to have higher chances of hyponatremia in various studies. ${ }^{[16,24-27]}$ The need for inotropes indicates a state of circulatory insufficiency which may act as a stimulus for $\mathrm{ADH}$ secretion, thereby causing a state of increased water retention and leading to hyponatremia.

With regards to IVFs, the majority of the patients $(66 \%)$ in hyponatremic group had received half-saline $(0.45 \% \mathrm{NaCl}$ with $5 \%$ dextrose), but there was no significant difference in the type of IVF used between the two groups. Even patients who received isotonic fluids had developed hyponatremia. The previous studies have shown that the use of hypotonic fluids is associated with increased risk of $\mathrm{HAH}$ when compared to isotonic fluids. ${ }^{[10-18]} \mathrm{A}$ study by Saba et al. in 2010 showed that sodium values showed a fall even in $19 \%$ of patients who received normal saline when compared to $24 \%$ in those receiving half-normal saline. They also reported that the use of half-normal saline in appropriate rate and volume has a similar risk of hyponatremia as that of normal saline. ${ }^{[28]}$ Similarly, in a study by Carandang et al. in 2013 , hyponatremia was seen even in $23 \%$ of children receiving isotonic fluids. ${ }^{[29]} 3 \% \mathrm{NaCl}$ was used in both groups as a part of standard therapy for patients with raised intracranial pressure. The use of $3 \% \mathrm{NaCl}$ was similar in both the groups.

Children in hyponatremic group had a higher length of PICU stay and ventilator days. Previous studies done in adult ICUs have shown worse mortality and morbidity profile in 
hyponatremic patients. ${ }^{[7-9]}$ Similar observations were reported by Luu et al. in children with bronchiolitis with HAH. ${ }^{[15]}$

Our study also has few limitations such as the exclusion of sources of water intake such as the amount of fluids received before PICU admission and occult sources of water-like parents giving drinks to children without informing the nurse which may not be included in the intake but affected the electrolyte balance. We could not evaluate the levels of $\mathrm{ADH}$ due to financial constraints, which would have helped to ascertain the status of $\mathrm{ADH}$ in a better manner. Furthermore, we did not estimate the urinary electrolyte and urinary osmolality profile in isonatremic patients, which could have helped us in comparing the sodium excretion state in both groups.

\section{Conclusions}

Based on our results, we conclude that HAH is common in PICU and is associated with poor morbidity profile. Based on our results, we also suggest the use of isotonic fluids alone may not completely eliminate the risk of developing hyponatremia in the presence of other risk factors. We suggest well-structured randomized control trials to assess the effect of risk factors on the development of HAH.

\section{Financial support and sponsorship}

Nil.

\section{Conflicts of interest}

There are no conflicts of interest.

\section{RefEREnCes}

1. Anderson RJ, Chung HM, Kluge R, Schrier RW. Hyponatremia: A prospective analysis of its epidemiology and the pathogenetic role of vasopressin. Ann Intern Med 1985;102:164-8.

2. Gill G, Huda B, Boyd A, Skagen K, Wile D, Watson I, et al. Characteristics and mortality of severe hyponatraemia - A hospital-based study. Clin Endocrinol (Oxf) 2006;65:246-9.

3. Zilberberg MD, Exuzides A, Spalding J, Foreman A, Jones AG, Colby $\mathrm{C}$, et al. Epidemiology, clinical and economic outcomes of admission hyponatremia among hospitalized patients. Curr Med Res Opin 2008;24:1601-8.

4. Arieff AI, Ayus JC, Fraser CL. Hyponatraemia and death or permanent brain damage in healthy children. BMJ 1992;304:1218-22.

5. Waikar SS, Mount DB, Curhan GC. Mortality after hospitalization with mild, moderate, and severe hyponatremia. Am J Med 2009;122:857-65.

6. Palmer BF. Hyponatremia in the Intensive Care Unit. Semin Nephrol 2009;29:257-70.

7. Arampatzis S, Frauchiger B, Fiedler GM, Leichtle AB, Buhl D, Schwarz C, et al. Characteristics, symptoms, and outcome of severe dysnatremias present on hospital admission. Am J Med 2012;125:1125e1-e7.

8. Funk GC, Lindner G, Druml W, Metnitz B, Schwarz C, Bauer P, et al. Incidence and prognosis of dysnatremias present on ICU admission. Intensive Care Med 2010;36:304-11.
9. DeVita MV, Gardenswartz MH, Konecky A, Zabetakis PM. Incidence and etiology of hyponatremia in an Intensive Care Unit. Clin Nephrol 1990;34:163-6.

10. Hoorn EJ, Geary D, Robb M, Halperin ML, Bohn D. Acute hyponatremia related to intravenous fluid administration in hospitalized children: An observational study. Pediatrics 2004;113:1279-84.

11. Bibi S, Bibi S, Gilani SY, Shah SR, ul Haq A, Billo AG. Frequency of hospital acquired hyponatremia in a pediatric tertiary care setting. J Ayub Med Coll Abbottabad 2015;27:560-3.

12. Armon K, Riordan A, Playfor S, Millman G, Khader A; Paediatric Research Society. Hyponatraemia and hypokalaemia during intravenous fluid administration. Arch Dis Child 2008;93:285-7.

13. Wattad A, Chiang ML, Hill LL. Hyponatremia in hospitalized children. Clin Pediatr (Phila) 1992;31:153-7.

14. Kannan L, Lodha R, Vivekanandhan S, Bagga A, Kabra SK, Kabra M. Intravenous fluid regimen and hyponatraemia among children: A randomized controlled trial. Pediatr Nephrol 2010;25:2303-9.

15. Luu R, DeWitt PE, Reiter PD, Dobyns EL, Kaufman J. Hyponatremia in children with bronchiolitis admitted to the pediatric Intensive Care Unit is associated with worse outcomes. J Pediatr 2013;163:1652-6.e1.

16. Eulmesekian PG, Pérez A, Minces PG, Bohn D. Hospital-acquired hyponatremia in postoperative pediatric patients: Prospective observational study. Pediatr Crit Care Med 2010;11:479-83.

17. Rey C, Los-Arcos M, Hernández A, Sánchez A, Díaz JJ, López-Herce J. Hypotonic versus isotonic maintenance fluids in critically ill children: A multicenter prospective randomized study. Acta Paediatr 2011;100:1138-43.

18. Montañana PA, Modesto i Alapont V, OcónAP, López PO, López Prats JL, Toledo Parreño JD. The use of isotonic fluid as maintenance therapy prevents iatrogenic hyponatremia in pediatrics: A randomized, controlled open study. Pediatr Crit Care Med 2008;9:589-97.

19. Spital A. Diuretic-induced hyponatremia. Am J Nephrol 1999;19:447-52.

20. Decaux G. The syndrome of inappropriate secretion of antidiuretic hormone (SIADH). Semin Nephrol 2009;29:239-56.

21. Shann F, Germer S. Hyponatraemia associated with pneumonia or bacterial meningitis. Arch Dis Child 1985;60:963-6.

22. Powell KR, Sugarman LI, Eskenazi AE, Woodin KA, Kays MA, McCormick KL, et al. Normalization of plasma arginine vasopressin concentrations when children with meningitis are given maintenance plus replacement fluid therapy. J Pediatr 1990;117:515-22.

23. Easley D, Tillman E. Hospital-acquired hyponatremia in pediatric patients: A review of the literature. J Pediatr Pharmacol Ther 2013;18:105-11.

24. Choong K, Arora S, Cheng J, Farrokhyar F, Reddy D, Thabane L, et al. Hypotonic versus isotonic maintenance fluids after surgery for children: A randomized controlled trial. Pediatrics 2011;128:857-66.

25. Au AK, Ray PE, McBryde KD, Newman KD, Weinstein SL, Bell MJ. Incidence of postoperative hyponatremia and complications in critically-ill children treated with hypotonic and normotonic solutions. J Pediatr 2008;152:33-8.

26. Singhi S. Hyponatremia in hospitalized critically ill children: Current concepts. Indian J Pediatr 2004;71:803-7.

27. Friedman JN; Canadian Paediatric Society, Acute Care Committee. Risk of acute hyponatremia in hospitalized children and youth receiving maintenance intravenous fluids. Paediatr Child Health 2013;18:102-7.

28. Saba TG, Fairbairn J, Houghton F, Laforte D, Foster BJ. A randomized controlled trial of isotonic versus hypotonic maintenance intravenous fluids in hospitalized children. BMC Pediatr 2011;11:82.

29. Carandang F, Anglemyer A, Longhurst CA, Krishnan G, Alexander SR, Kahana M, et al. Association between maintenance fluid tonicity and hospital-acquired hyponatremia. J Pediatr 2013;163:1646-51. 